\title{
Evaluation of Coordination and Optimal Route of Military-Military Integration Logistics System
}

\author{
Ying Xu ${ }^{1,}$, Jiongqi Wang ${ }^{1}$, Xiaogang Pan $^{2}$, Haiyin Zhou ${ }^{1}$, Zhangming $\mathrm{He}^{1}$, Bowen Hou ${ }^{1}$ \\ ${ }^{1}$ College of Liberal Arts and Sciences, National University of Defense Technology, Changsha, China \\ ${ }^{2}$ College of System Engineering, National University of Defense Technology, Changsha, China
}

\section{Email address:}

562365469@qq.com (Ying Xu),wjq_gfkd@163.com (Jiongqi Wang), panxiaogang_nudt@163.com (Xiaogang Pan), gfkd_zhy@sina.com (Haiyin Zhou), hzmnudt@sina.com (Zhangming He), houbowen95@126.com (Bowen Hou)

${ }^{*}$ Corresponding author

\section{To cite this article:}

Ying Xu, Jiongqi Wang, Xiaogang Pan, Haiyin Zhou, Zhangming He, Bowen Hou. Evaluation of Coordination and Optimal Route of Military-Military Integration Logistics System. Science Discovery. Vol. 8, No. 5, 2020, pp. 113-121. doi: 10.11648/j.sd.20200805.17

Received: September 1, 2020; Accepted: October 9, 2020; Published: October 17, 2020

\begin{abstract}
In order to promote the deep development strategy of national civil-military integration, establish a mutual coupling and coordinated development of military local logistics system, and promote the sound and rapid development of national economic development and national defense modernization, this paper studies the construction and coordination evaluation of civil-military integration logistics system from the field of logistics. This paper briefly describes the relationship between military logistics and civil logistics, at the same time, according to the current situation of domestic epidemic situation, on the basis of the military civilian integration logistics system constructed by scholars, an emergency response mechanism is added to constitute the index system and evaluation model of the coordination degree of the military civilian integration logistics system. This paper uses fuzzy analytic hierarchy process (FAHP) to analyze the new evaluation model of military civil integration logistics coordination degree, and the evaluation matrix of each criterion relative to the overall evaluation objective is obtained. According to the evaluation matrix, and puts forward corresponding suggestions and opinions aiming at the possible problems existing in the current military civil integration logistics system, so as to provide reference for the construction and adjustment of the military civilian integration logistics system by the relevant national departments in the future.
\end{abstract}

Keywords: Integrated Civil-military Logistics System, Coordination Evaluation, Emergency Response System, Fuzzy AHP

\section{基于模糊层次分析法的军民融合物流体系协调度评价}

\author{
徐影 $^{1}$, 王畑琦 $^{1}$, 潘晓刚 ${ }^{2}$, 周海银 ${ }^{1}$, 何章鸣 ${ }^{1}$, 侯博文 ${ }^{1}$ \\ ${ }^{1}$ 国防科技大学文理学院, 长沙, 中国 \\ 2国防科技大学系统工程学院, 长沙, 中国
}

\section{邮箱}

562365469@qq.com(徐影)，wjq_gfkd@163.com（王昫琦）, panxiaogang_nudt@163.com（潘晓刚），

gfkd_zhy@sina.com(周海银), hzmnudt@sina.com（何章鸣）, houbowen95@126.com（侯博文）

\begin{abstract}
摘要: 为推进国家军民融合深度发展战略, 建立相互耦合、协调发展的军地物流体系, 促进国家经济发展和国防现代 化又好又快发展, 文章从物流领域对军民融合物流体系的构建及协调度评价进行研究。文章简要阐述了军事物流与民 用物流的相互关系, 同时针对国内疫情现状, 在现学者们构建的军民融合物流体系基础上新增应急响应体制机制构成 军民融合物流体系协调度指标体系及评价模型。采用模糊层次分析法, 对新构建的军民融合物流协调度评价模型进行 实例分析, 得到各准则相对于总体评价目标的评价矩阵, 并根据评价矩阵给出针对当前军民融合物流体系可能存在的 问题提出相应建议和意见，为未来国家相关部门对军民融合物流体系的构建及调整提供参考。
\end{abstract}


关键词: 军民融合物流系统, 协调度评价, 应急响应体制, 模糊层次分析法

\section{1. 引言}

党的十九大报告强调, “形成军民融合深度发展格局”, 由此军民融合这一课题成为社会各界的研究热点。物流领 域作为军民融合发展格局的重点领域之一, 有助于军民物 流优势互补，提升军事物流整体运行质量。由于军事物流 与地方物流在物流设备、设施、管理、技术、服务、人才 等方面存在广泛的通用性和互补性, 使得军地双方可以根 据国防和经济发展的需求, 建立相互耦合、协调发展的军 地物流体系, 以促进国家经济发展和国防现代化又好又快 发展 [1]。发展军民融合物流, 不仅能统筹军民物流资源, 提高社会物流的利用率和经济效益[2], 而且有利于将军队 先进技术转为民用, 提高社会物流的技术水平和效率 [3], 进一步促进社会物流的发展。

军事物流与地方物流之间是一种相辅相成、相互促进 的发展关系，它们的耦合不仅有力地保证了国民经济和国 防建设的有序进行, 也支撑军队后勤保障的健康发展 [1]。 军民融合物流系统耦合协调度评价, 即是通过研究考察军 民融合活动中，军地物流双方所拥有的物流资源（包括物 流基础设施、信息系统、人力资源等) 以及应急响应的耦 合协调状况并对此进行评价, 以客观反映军民融合物流系 统的发展水平。

我国军事物流长期保持相对封闭状态, 与社会物流的 融合正处在由初步融合向深度融合的过渡阶段, 仍存在物 流资源整合度较低、军民物流沟通渠道不畅、物流基础设 施重复建设、军民物流标准化程度有待提高等问题, 极大 制约了军民物流的融合发展 [4]。同时近些年, 灾害不断侵 袭我国，1998年的洪涝侵袭、2003年的非典型肺炎爆发、 2008年的汶川大地震等给全国人民造成了极大的生命财 产损失。由2019新型冠状病毒的蔓延传播并在全中国、甚 至全世界范围造成的肺炎疫情感染, 更是给我国和世界人 民带来了前所未有的打击与考验。因此, 我国急需建设结 构合理、互融互通的军民融合物流体系, 聚焦军用物流系 统和民用物流系统运行时的耦合协调度, 并重视军民融合 物流系统对国家突发公共事件的应急处理能力。

目前, 就如何在军民融合的大背景下发展军民融合物 流, 学者们分别从信息化、标准化、发展机制等方面给出 了建议。曹景键等提出了 [5]通过建立基于计算机辅助后勤 保障系统的军民融合信息体系; 王风忠 [6]等提出应从通用 基础、技术、信息、管理、服务五个方面完善军民融合物 流标准化体系建设; 张中强[7]探讨了军民融合物流的融化 我发展机制, 并将融合发展机制从动态发展的角度分为形 成机制、成长机制和协调机制; 古贞 [4]等从系统角度对军 民融合物流问题进行研究, 探讨构建军民融合物流体系。 而袁科峰 [8]等分析了军事物流系统和民用物流系统的耦 合内容, 并提出军民融合式物流系统耦合协调量化模型。

综上可知, 现有学者对于军民融合物流的研究已经十 分广泛, 并取得一定的成果, 但未将军民融合物流在重大 灾情时的应急处理能力作为体系建设的另一重要部分, 并
缺乏对军民融合物流体系的耦合协调度的实例分析和评 价。

本文综合利用系统学的数学知识, 对现阶段军民融合 物流系统运行时的耦合协调度进行研究和评价, 采用模糊 层次分析法, 研究构建了基于模糊层次分析法且具有应急 物流保障效能的军民融合物流协调度评价指标体系模型, 并结合数值仿真算例, 得到了军民融合物流协调度影响因 素权重总排序以及评价等级, 为后续国家相关人员对军民 融合物流系统的深层次融合与协调发展提供相应理论指 导与借鉴。

\section{2. 军民融合物流体系构建}

\section{1. 军民融合物流体系构建的基本原则}

军民融合物流系统协调度的评价指标体系是对军民 融合物流系统进行耦合协调度评价的依据, 也是衡量信息 公开评价是否客观、公正、全面的标尺, 关系到整个评价 过程的准确性及标准性。构建军民融合物流系统协调度评 价指标体系需要遵循以下几个原则:

（1）国家主导原则[4]。把握国家在军队物流和社会 物流融合中的主导地位, 确保军民融合物流各领域、各部 门、各层级的统筹协调安排, 在综合运用规划引导、体制 创新、法治保障等手段的基础上, 推动军民融合物流的深 度发展, 并发挥国家的协调和监督作用。

（2）整体性原则。军民融合物流系统协调度评价必 须坚持整体性和系统性的原则, 协调度评估要能充分反映 军民融合物流系统中各部门的地位作用及相互关系, 遵循 定性评估和定量评估相结合、内部评估和外部评估相结合 的方法, 注重协调关系, 既要有主次之分, 又不能以偏概 全。

(3) 可扩展性原则[9]。军民融合物流体系要适应并 支撑因科技进步促进的生产工艺不断变革、产品持续更新, 能在国家或军队面临重大灾难和战时继续保障物流服务 优质、高效、稳定、便捷, 始终将人民群众放在第一位, 最大化降低人民损失。

\section{2. 军民融合物流体系的组成}

军民融合物流体系以信息共享平台为核心，运用物联 网、计算机、卫星应用、大数据等技术, 实现军民之间, 不同层次、不同部门间的物流信息及信息产品的共享和共 用。军民融合物流体系应包含组织管理体系、信息共享体 系、物流绩效评估系统、应急响应体制机制、物资运输体 系、物流保障体系和物流运输运行机制 7 个子体系, 它们 相互促进、相互制约, 共同支撑军民融合物流体系的运行 发展。具体框架如图1所示: 


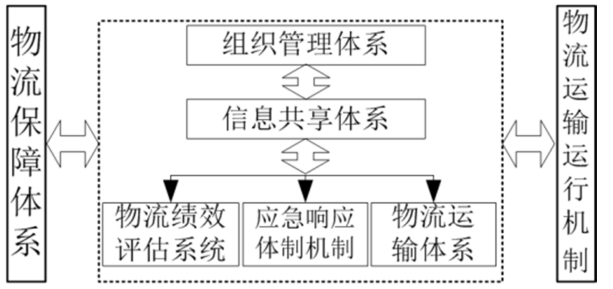

图1 军民融合物流体系框架结构。

组织管理体系以信息共享体系为平台支撑，是实现军 民物流组织管理一体化、在军民物流之间建立起的统一领 导、军民协调统一的组织管理体系[4]。

信息共享体系由信息系统支撑，各信息模块发挥不同 功能，共同实现军民融合物流信息资源的共享。

物流绩效评估系统从物流行业总产值、军事物流产值、 民用物流产值、军事物流成本、民用物流成本以及物流总 成本占GDP比重对军民融合物流体系的运营绩效进行评估。

应急响应体制机制是军民融合物流体系在应对国家 突发重大灾情、保护人民财产生命安全必不可少的运行机 制, 以确保我国受到灾害的地方得到充足的救援物资, 第 一时间对受灾人民进行救助金额转移, 减少因时间的问题 带来更多的伤亡。应急响应体制机制的作用发挥首先从战 略规划层面为军民融合物流体系的行动做出指导与安排, 相应的应急物流法规规范使军民融合物流系统发挥应急

响应能力时有法可依，政府和社会的财政资金支持、 市场医疗行业合作，共同支撑着军民融合物流体系在物资 应急采购与投送工作顺利完成。

物流运输体系是军民融合物流体系发挥运输功能的 硬件设施和基础, 是统筹国家、军队和社会的交通运输设 施运载工具, 其综合运用水路、铁路、航空等运输方式, 调整和优化物资运输网络, 形成有机衔接的军民物资运输 体系。物流运输体系应包含交通基础设施网络系统和一体 化军民运输系统, 从基础设施与军队信息化建设共同构建 物流运输体系。

物流保障体系从法律法规、人才培养、标准规范等方 面保障军民融合物流体系的稳固、持续运行。物流法律法 规体系通过立法, 使军民融合物流的各项活动都有法可依, 为建设军民融合物流体系提供法律依据[4]。军民融合物流 人才培养是军民融合深度发展的重要环节和硬件设施。物 流标准化体系能有效避免军用与民用、民用内部的标准不 统一问题。

物流运输运行机制是实现军民融合物流体系整体内 在科学合理运行方式的基本准则, 也是引导和制约军民融 合物流体系各要素之间相互联系和相互作用的相应制度。 物流运输运行机制包括安全保密机制、协调运作机制、绩 效评估与激励机制、平战转换机制、企业准入与退出机制。

\section{3．军民融合物流体系协调度指标体系及评价模 型}

\section{1. 军民融合物流体系协调度评价指标构建}

协调度评价的结果直接受到选取的评价指标的影响。 军民融合物流系统协调度评价的指标选取应从系统论角
度出发, 既要考虑系统整体功能的实现, 也要考虑各部分 间的相互关系，同时注重各层级的设计，以实现军民融合 物流系统耦合协调度最优。本文以军民融合物流系统协调 度为评价目标, 在充分遵循评价指标构建原则的基础上, 得到如表1所示的军民融合物流系统协调度评价指标体系:

表1 军民融合物流系统协调度评价指标体系。

\begin{tabular}{|c|c|c|}
\hline 目标层U & 准则层A & 指标层B \\
\hline $\begin{array}{l}\text { 军民融合物 } \\
\text { 流系统协调 } \\
\text { 度U }\end{array}$ & $\begin{array}{l}\text { 组织管理体系 A4 } \\
\text { 物流运输运行机制 A5 }\end{array}$ & 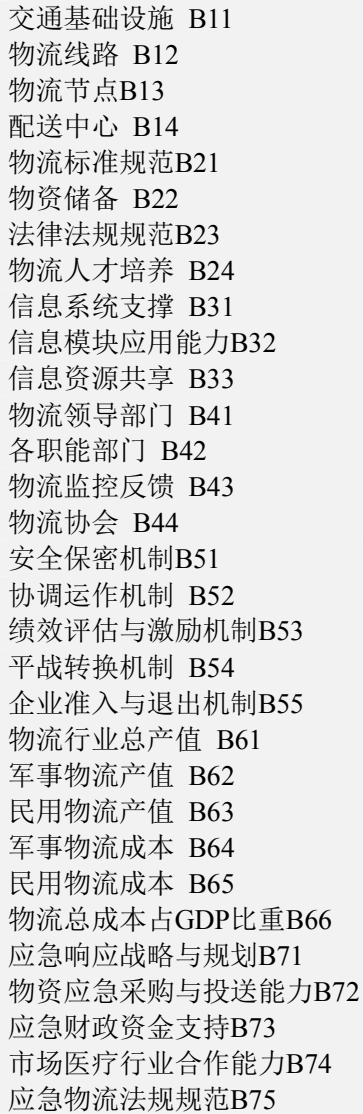 \\
\hline
\end{tabular}

\section{2. 基于模糊层次分析法的军民融合物流系统协调度评 价模型构建}

\subsection{1. 层次分析法评价模型}

层次分析法是由T.L.Saaty等研究学者在1970年初提 出, 该算法是定量和定性分析相结合的多目标决策方法, 能有效分析目标准则体系层次间的非序列关系, 有效地综 合测度决策者的判断和比较 [10]。层次分析法的原理就是 为了方便组织对可行方案进行最优化选择, 把不同方案的 优点和缺点做一个排列等级 [11]。该方法的具体运行原理 是针对复杂对象的, 复杂对象即是总目标, 将总目标中多 种不同的要素, 根据彼此之间的关联进行递阶层级划分, 通过给研究学者发放调查问卷从而获取学者们对于不同 要素的定性分析, 构建判断矩阵, 通过计算得到权重, 通 过不同的数值的权重就能看出各要素重要程度的不同, 并 对其进行依次排列, 最终得到评价结果, 选定最优方案 [12]。

层次分析法建模的步骤包括: 建立各层次间的递阶结 构模型及各因素从属关系; 判断矩阵的构建; 指标权值的 
确定; 单一指标层级的排列次序和判断矩阵的一致性检测。 具体实现步骤如下:

（1）建立各层次间的递阶结构模型

在评价过程中应用到的层次分析法, 要对评价对象进 行分层, 明确评价要素之间的等级隶属关系, 并构造各层 次间的递阶结构模型。层次分析模型普遍由四个层次构成: 目标层 $\mathrm{U}$, 准则层 $\mathrm{A}$, 指标层以 $\mathrm{B}$ 及方案层 $\mathrm{C}[13]$ 。目标层 $\mathrm{U}$ 就是层次分析的目标指数, 是分析问题的最终目标, 目标
层中只包含一个因素; 准则层是该模型的中间环节, 为达 到评价目标的多种不同影响因素都包含在其中, 原则上允 许多层次化, 但本文中为了增加准确性, 只设置一层准则 层; 指标层包含了影响各指标优劣的评价对象, 直接反应 了各评估对象的综合影响力; 方案层包含看若干可供选择 的目标实现方案, 一般在最优方案选择时使用, 本文暂时 不应用 递阶层次结构图如图2所示:

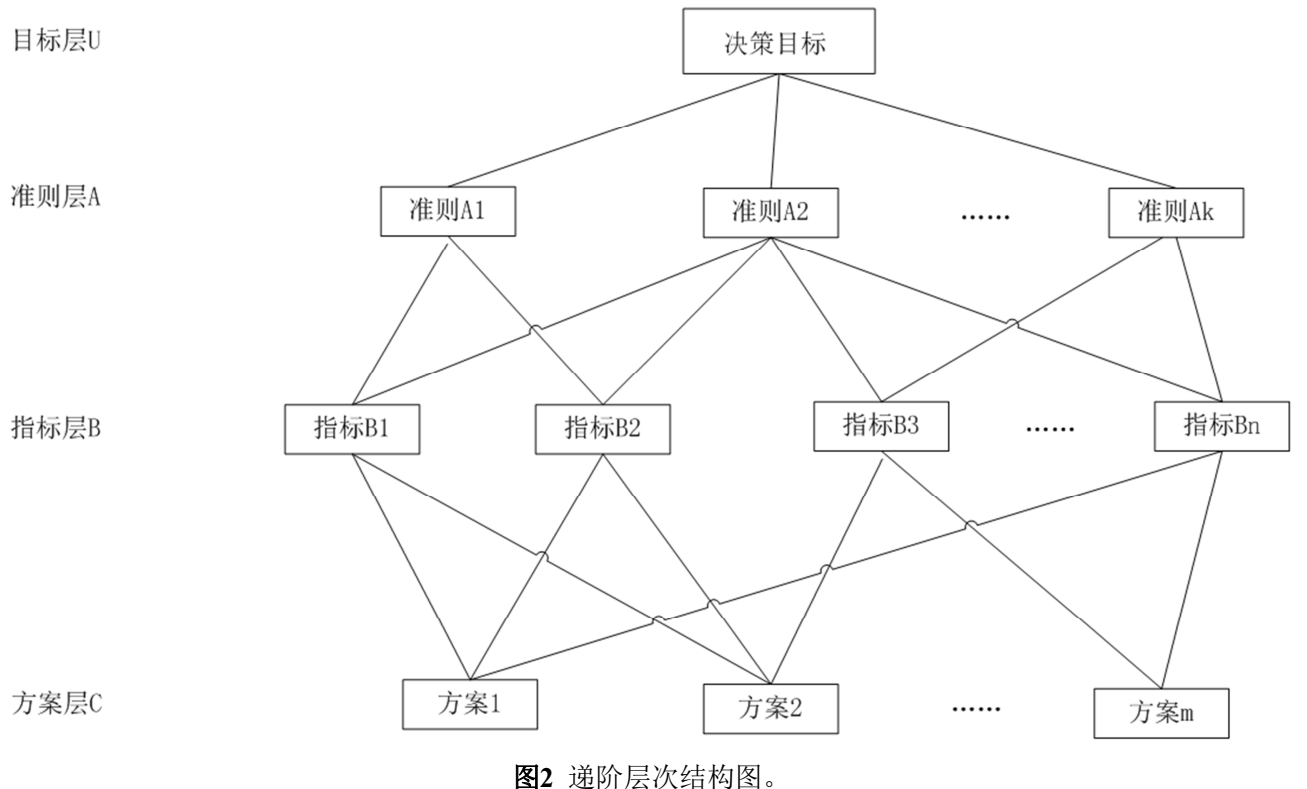

本文所建立的军民融合物流体系协调度评价模型中 的目标层U, 即是对军民融合物流体系协调度进行评价, 并由七种准则共同作为其协调度评价的判别标准, 它们分 别是：物流运输体系 $\mathrm{A} 1$ 、物流保障体系 $\mathrm{A} 2$ 、信息共享体 系A3、组织管理体系A4、物流运输运行机制 $\mathrm{A} 5$ 、物流绩 效评估系统A6和应急响应体制机制 $\mathrm{A} 7$ 。准则层的各个准 则由影响该准则相对于最终目标重要程度的因素构成, 物 流运输体系A1分别由交通基础设施 B11、物流线路 B12、 物流节点B13、配送中心B14影响因素组成; 物流保障体 系A2 由物流标准规范B21、物资储备 B22、法律法规规 范B23 、物流人才培养 B24影响因素组成; 信息共享体 系A3由信息系统支撑 B31、信息模块应用能力B32、信 息资源共享 B33影响因素组成; 组织管理体系A4由物流 领导部门 B41、各职能部门 B42、物流监控反馈 B43、 物流协会 B44影响因素组成; 物流运输运行机制A5 由安 全保密机制B51、协调运作机制 B52、绩效评估与激励机 制B53、平战转换机制 B54、企业准入与退出机制B55影
响因素组成、物流绩效评估系统A6由物流行业总产值 B61、军事物流产值 B62、民用物流产值 B63、军事物流 成本 B64、民用物流成本 B65、物流总成本占GDP比重 B66影响因素组成; 应急响应体制机制A7由应急响应战略 与规划B71、物资应急采购与投送能力B72、应急财政资 金支持B73、市场医疗行业合作能力B74、应急物流法规 规范B75影响因素组成, 它们共同构成军民融合物流体系 协调度评价模型的递阶层次图。

（2）构建判断矩阵

根据递阶结构模型图, 针对同一层级的多种要素相对 于上一层的重要程度进行两两比较, 得到判断矩阵 $A\left[a_{i j}\right]_{m \times m}, m$ 表示被评价要素的个数。用 9 个数字来描 述人们在表达两个因素在某种属性下的相对强度时所采 用的相等、较强（弱）、明显强（弱）、很强（弱）等类 语言。1-9比例尺标度法的内容[14]见下表2:

表2 1-9比例尺度的含义。

\begin{tabular}{ll}
\hline 标度值 $\left(a_{i j}\right)$ & 含义 \\
\hline 1 & 表示两个元素相比, 同等重要 \\
3 & 表示两个元素相比, 前者比后者稍重要 \\
5 & 表示两个元素相比, 前者比后者明显重要 \\
7 & 表示两个元素相比, 前者比后者强烈重要 \\
9 & 表示两个元素相比, 前者比后者极端重要 \\
$2 、 4 、 6 、 8$ & 表示上述相邻判断的中间值 \\
$1 / a_{i j}$ & 如果元素 $i$ 与 $j$ 的重要性比率是 $a_{i j}$, 那么元素 $j$ 与元素 $i$ 重要性比率是 $a_{i j}=1 / a_{i j}$ \\
\hline
\end{tabular}


(3) 确定各判断矩阵的权重系数

本文采用和积法确定各判断矩阵的权重系数。根据判 断矩阵求其最大特征根 $\lambda_{\max }$ 及相应的标准化特征向量 $W=\left[w_{1}, w_{2}, \cdots, w_{m}\right] 。 W$ 经过归一化处理后即可得到该层 对于上一层某因素相对重要性的权重[19]。

$\lambda_{\text {max }}$ 及 $W$ 的算式如下 [11]:

1 ) 计算判断矩阵 $A$ 每行每个元素的乘积 $m_{i}=\coprod_{i=1}^{n} a_{n}, \quad i=1,2, \cdots, n$ 。

2) 计算 $m_{i}$ 的 $n$ 次方根 $\overline{w_{i}}=\sqrt[n]{m_{i}}$ 。

3 ) 对向量 $\bar{W}=\left[w_{1}, w_{2}, \cdots, w_{m}\right]$ 进行归一化处理, 最终 得到 $W=\left[w_{1}, w_{2}, \cdots, w_{m}\right]$ 就是计算得到的结果向量。

4 ) 计算矩阵的最大特征根 $\lambda_{\max }$ 。 $\lambda_{\text {max }}=\frac{1}{n} \sum_{i=1}^{n} \frac{(A W)_{i}}{w_{i}}$ 。对于任意的 $i=1,2, \cdots, n, \quad(A W)_{i}$ 为向量 $A W$ 的第 $i$ 项元素。

(4) 判断矩阵的一致性检验

确定比较判断是否具有一致性是层次分析法中的另 一个重点。层次分析法要求在两两比较时进行一致性检验, 以确保决策者在对两两比较时既不是不一致的、也不是随 机进行的 [16]。判断矩阵的不一致性, 究其原因, 主要有 两个, 一是专家在进行两两比较时的价值取向和定级技巧, 二是重要性等级赋值的非等比性。因此, 当判断矩阵的阶 数 $\mathrm{n}>2$ 时, 通常难于构造出满足一致性条件的矩阵来。但 判断矩阵偏离一致性条件应有一个度, 举例来说, 一个出 现“A元素比B元素重要, B元素比C元素重要, $C$ 元素又比 A元素重要”之类有悖于常理的判断矩阵, 是难以令人置信 的。为此, 必须对判断矩阵是否可接收进行鉴别。其步骤 如下[18]:

1) 计算一致性指标 $C I=\frac{\lambda_{\max }-n}{n-1}, n$ 为判断矩阵的 阶数, $\lambda_{\text {max }}$ 为判断矩阵的最大特征根;

2) 计算相对一致性指标 $C R=\frac{C I}{R I}$, 其中 $R I$ 为平均 随机一致性指标。通常情况下当 $C R \leq 0.1$, 一致性检验通过, 否则, 当 $C R \geq 0.1$ 时要重新构造判断矩阵。

\subsection{2. 模糊综合评价模型}

模糊综合评价法是当前在实践活动中使用范围比较 广发的、有一定实用价值的基于模糊知识的数学评价法。 该方法能较全面地汇总各评价主体的意见, 从总体上对被 评价主体的优秀程度做出判断。原理就是: 把被评价的复 杂对象分解为多个不同的要素, 这些要素构成的集合叫做 因素集 $U$, 把分解出来的不同要素归类到不同的评估级别, 这些评估级别构成一个集合叫做评语集 $V$, 利用数学算式 得出每个要素本身隶属于哪个评估级别形成评价矩阵 $R$, 将已经确定了的权值 $W$ 与该矩阵进行结合, 最终得到数 量化的评估结果[9]。

(1) 评价因素集和评语等级的确定
假 设 $U=\left[u_{1}, u_{2}, \cdots, u_{m}\right]$ 为评价因素集, $V=\left[v_{1}, v_{2}, \cdots, v_{n}\right]$ 为评语等级集。评语等级集 $V=\left[v_{1}, v_{2}, \cdots, v_{n}\right]$ 为评价主体对评价目标作出的总体评估 结果的集合, 本文将军民融合物流系统耦合协调度评价的 最终结果分为 4 个层级： $v_{1}=$ 优秀、 $v_{2}=$ 良好、 $v_{3}=$ 中等、 $v_{4}=$ 较差 [17]。根据人们对事物进行判定的行为习惯以及 最大隶属度的需要, 按照归一化原则分别将各评语等级赋 值, 评语等级度量的变化范围在 $[0,1]$, 评价的等级若为 $n$ 级，则区间的长度就为 $1 / \mathrm{n}$ ，评价的区间为 $[0,1 / \mathrm{n}],[1 / \mathrm{n}, 2 / \mathrm{n}],[3 / \mathrm{n}, 4 / \mathrm{n}], \ldots,[\mathrm{i} / \mathrm{n},(\mathrm{i}+1) / \mathrm{n}], \ldots,[(\mathrm{n}-1) / \mathrm{n}, 1]$, 式中 $\mathrm{i}=1,2, \ldots, \mathrm{n}[13]$ : 则 $v_{4}=$ 较差的最大隶属度范围就是 $[0,0.25]$; $v_{3}=$ 中等的最大隶属度范围就是 $[0.25,0.5] ; v_{2}=$ 良好的最大 隶属度范围就是 $[0.5,0.75] ; v_{1}=$ 优秀的最大隶属度范围就 是 $[0.75,1]$ 。本文的评价因素集就是上文中建立的军民融合 物流系统协调度评价指标。设军民融合物流系统协调度一 级评价指标层集合为 $U_{1}=\left[A_{1}, A_{2}, A_{3}, A_{4}, A_{5}, A_{6}, A_{7}\right]$,一级评 价指标中各指标分别代表军民融合物流系统协调度评价 中的七个一级指标, 即物流运输体系 $A_{1}$ 、物流保障体系 $A_{2}$ 、 信息共享体系 $A_{3}$ 、组织管理体系 $A_{4}$ 、物流运输运行机制 $A_{5}$ 、物流绩效评估系统 $A_{6}$ 和应急响应体制机制 $A_{7}$ 。物流 运输体系评价指标集 $U_{A 1}=\left[B_{11}, B_{12}, B_{13}, B_{14}\right]$ 、物流保障体 系 $U_{A 2}=\left[B_{21}, B_{22}, B_{23}, B_{24}\right]$ ，信 息共享体系 $U_{A 3}=\left[B_{31}, B_{32}, B_{33}\right]$ 、组 织管 理 体 系 $U_{A 4}=\left[B_{41}, B_{42}, B_{43}, B_{44}\right]$ 、物流运输运行机制 $U_{A 5}=\left[B_{51}, B_{52}, B_{53}, B_{54}, B_{55}\right]$ 、物流绩效评估系统 $U_{A 6}=\left[B_{61}, B_{62}, B_{63}, B_{64}, B_{65}, B_{66}\right]$ 、应急响应体制机制 $U_{A 7}=\left[B_{71}, B_{72}, B_{73}, B_{74}, B_{75}\right]$ 。

(2) 单层次模糊综合评价模型

首先对评价因素集中的每项评价指标进行单指标评 价, 确定准则层中各指标层的评价指标对于评判集 $V$ 中各 种评价的隶属度 $r_{i j}$, 这样就得出第 $i$ 个因素 $u_{i}$ 的单因素评 判集 $r_{i}=\left[r_{i 1}, r_{i 2}, \cdots, r_{i n}\right], m$ 个因素的评价集就构造出了一 个评价矩阵

$$
R=\left[\begin{array}{cccc}
r_{11} & r_{12} & \cdots & r_{1 n} \\
r_{21} & r_{22} & \cdots & r_{2 n} \\
\vdots & \vdots & \ddots & \vdots \\
r_{m 1} & r_{m 2} & \cdots & r_{m n}
\end{array}\right]
$$

（3）模糊综合评价

将上述通过层次分析法计算得到的每个评价指标权 值 $W$ 与通过上一步对评价因素集进行单层次模糊综合评 价得到的结果 $R$ 评价矩阵进行合成, 确定军民融合物流系 统耦合协调度评价向量 $B$ 。 


$$
B=W \times R=\left[w_{1}, w_{2}, \cdots, w_{m}\right] \times\left[\begin{array}{cccc}
r_{11} & r_{12} & \cdots & r_{1 n} \\
r_{21} & r_{22} & \cdots & r_{2 n} \\
\vdots & \vdots & \ddots & \vdots \\
r_{m 1} & r_{m 2} & \cdots & r_{m n}
\end{array}\right]
$$

\section{4. 军民融合物流体系协调度评价实例分析}

\section{1. 指标权重的确立}

通过向居民、专家以及军民融合物流各部门工作人员 发放军民融合物流体系协调度评价的调查问卷, 获取具体 的评价数据。问卷的内容主要由用于构造判断矩阵的1-9 比例尺标度表和用于构造评价矩阵的归一化评价指标构 成。整理相关数据, 进行军民融合物流体系协调度评价的 实例分析。

首先, 根据调查问卷获取的相关数据进行层次分析法 中判断矩阵的建立, 用和积法来确定每个判断矩阵的权值 系数 $\lambda_{\text {max }}$ 及 $W$, 并对每个判断矩阵进行一致性检验。具 体的数据和运算过程如下:

（1）目标层U与准则层 $\mathrm{A}$ 之间的判断矩阵:

$$
W=[0.1964,0.0531,0.3306,0.0806,0.0352,0.1029,0.1959], \quad \lambda_{\max }=7.3799
$$

同时计算出 $C I=0.0633, C R=0.0480<0.1$, 由此可判 断出此判断矩阵满足一致性检验。

$$
\text { 由 权 重 系 数 }
$$

$$
W=[0.1964,0.0531,0.3306,0.0806,0.0352,0.1029,0.1959]
$$

可以得出各准则相对于总目标军民融合物流系统协 调度的重要性大小降序排列为: 信息共享体系 $\mathrm{A} 3$ 、物理运 输体系A1、应急响应体制机制A7、物流绩效评估系统A6、 组织管理体系A4、物流保障体系A2、物流运输运行机制 A5。

(2) 准则层各因素 $\mathrm{A}$ 与指标层 $\mathrm{B}$ 之间的判断矩阵:

建立指标层相对于各自准则层的判断矩阵, 由七个准 则可得出七种不同的判断矩阵, 分别为A1、A2、A3、A4、

A5、A6和 A7, 七种判断矩阵为:

$$
A_{1}=\left[\begin{array}{cccc}
1 & 5 & 3 & 5 \\
1 / 5 & 1 & 1 / 3 & 3 \\
1 / 3 & 3 & 1 & 3 \\
1 / 5 & 1 / 3 & 1 / 3 & 1
\end{array}\right]
$$

其 中 判断矩阵 $\mathrm{A}_{1}$ 的权重系数 $W_{1}=[0.5495,0.1293,0.2476,0.0736], \lambda_{\max }=4.1981, \quad C I$ $=0.660, \quad C R=0.0734<0.1$, 满足一致性检验。

$$
A_{2}=\left[\begin{array}{cccc}
1 & 3 & 5 & 6 \\
1 / 3 & 1 & 2 & 3 \\
1 / 5 & 1 / 2 & 1 & 2 \\
1 / 6 & 1 / 3 & 1 / 2 & 1
\end{array}\right]
$$

根据问卷调查中1-9比例尺标度法获取的评价数据, 建立目标层军民融合物流系统协调度评价U和各准则层 $\mathrm{A}$ 之间的判断矩阵。其中, 准则层中的物流运输体系A1比物 流保障体系A2明显重要, 因此判断矩阵的第一行第二列元 素应填 5 , 反之第二行第一列元素为其导数 $1 / 5$ 。按照此评 价方法, 建立如下的判断矩阵。

$$
U=\left[\begin{array}{ccccccc}
1 & 5 & 1 / 2 & 3 & 5 & 2 & 1 \\
1 / 5 & 1 & 1 / 5 & 1 / 3 & 3 & 1 / 3 & 1 / 3 \\
2 & 5 & 1 & 5 & 5 & 5 & 2 \\
1 / 3 & 3 & 1 / 5 & 1 & 3 & 1 / 2 & 1 / 3 \\
1 / 5 & 1 / 3 & 1 / 5 & 1 / 3 & 1 & 1 / 3 & 1 / 5 \\
1 / 2 & 3 & 1 / 5 & 2 & 3 & 1 & 1 / 3 \\
1 & 3 & 1 / 2 & 3 & 5 & 3 & 1
\end{array}\right]
$$
系数:

根据上文所给的算法公式, 计算出判断矩阵 $U$ 的权重

其 中判断矩阵 $\mathrm{A}_{2}$ 的权重系数 $W_{2}=[0.5767,0.2216,0.1251,0.0766], \lambda_{\max }=4.0340, \quad C I$ $=0.0113, C R=0.07126<0.1$, 满足一致性检验。

$$
A_{3}=\left[\begin{array}{ccc}
1 & 3 & 4 \\
1 / 3 & 1 & 2 \\
1 / 4 & 1 / 2 & 1
\end{array}\right]
$$

其中判断矩阵 $\mathrm{A}_{3}$ 的权重系数 $W_{3}=[0.625,0.2385,0.1365], \lambda_{\max }=3.0183, C I=0.0091$, $C R=0.0158<0.1$, 满足一致性检验。

$$
\mathrm{A}_{4}=\left[\begin{array}{cccc}
1 & 3 & 1 / 2 & 5 \\
1 / 3 & 1 & 1 / 3 & 3 \\
2 & 3 & 1 & 5 \\
1 / 5 & 1 / 3 & 1 / 5 & 1
\end{array}\right]
$$

其 中判断矩阵 $\mathrm{A}_{4}$ 的权重系数 $W_{4}=[0.3248,0.1486,0.46,0.0665], \lambda_{\max }=4.1042, C I$ $=0.0347, C R=0.0386<0.1$, 满足一致性检验。

$$
A_{5}=\left[\begin{array}{ccccc}
1 & 3 & 3 & 5 & 5 \\
1 / 3 & 1 & 2 & 3 & 3 \\
1 / 3 & 1 / 2 & 1 & 3 & 3 \\
1 / 5 & 1 / 3 & 1 / 3 & 1 & 2 \\
1 / 5 & 1 / 3 & 1 / 3 & 1 / 2 & 1
\end{array}\right]
$$


其 中判断矩阵 $\mathrm{A}_{5}$ 的权重系数 $W_{5}=[0.4593,0.2239,0.1695,0.0839,0.0635], \lambda_{\max }=5.1727$, $C I=0.0432, \quad C R=0.0385<0.1$, 满足一致性检验。

$$
A_{6}=\left[\begin{array}{cccccc}
1 & 3 & 3 & 4 & 4 & 2 \\
1 / 3 & 1 & 2 & 3 & 4 & 1 / 3 \\
1 / 3 & 1 / 2 & 1 & 2 & 3 & 1 / 3 \\
1 / 4 & 1 / 3 & 1 / 2 & 1 & 2 & 1 / 3 \\
1 / 4 & 1 / 4 & 1 / 3 & 1 / 2 & 1 & 1 / 3 \\
1 / 2 & 3 & 1 / 3 & 3 & 3 & 1
\end{array}\right]
$$

其 中判断矩阵 $\mathrm{A}_{6}$ 的权重系数 $W_{6}=[0.3588,0.1717,0.117,0.0763,0.0554,0.2208] ， \lambda_{\max }$ $=6.1118, C I=0.0224, C R=0.0185<0.1$, 满足一致性检验。

$$
\mathrm{A}_{7}=\left[\begin{array}{ccccc}
1 & 1 / 2 & 2 & 3 & 3 \\
2 & 1 & 3 & 5 & 5 \\
1 / 2 & 1 / 3 & 1 & 2 & 2 \\
1 / 3 & 1 / 5 & 1 / 2 & 1 & 1 / 2 \\
1 / 3 & 1 / 5 & 1 / 2 & 2 & 1
\end{array}\right]
$$

其 中判断矩阵 $\mathrm{A}_{7}$ 的权重系数 $W_{7}=[0.2491,0.4360,0.1481,0.0716,0.0951], \lambda_{\text {max }}=5.0738$, $C I=0.0185, \quad C R=0.0165<0.1$, 满足一致性检验。

\section{2. 模糊综合评价}

统计调查问卷中对军民融合物流系统协调度评价的 指标层 $\mathrm{B}$ 的评价数据, 经整合后得到军民融合物流体系协 调度评价数据如表 3 :

\begin{tabular}{|c|c|c|c|c|c|c|c|c|c|}
\hline \multirow{2}{*}{$\mathbf{E} 0^{1}$} & \multirow{2}{*}{$\mathrm{FEO}^{2}$} & \multirow{2}{*}{$F^{3}$} & \multirow{2}{*}{$\mathrm{SEO}^{4}$} & \multirow{2}{*}{$\mathrm{SW}^{5}$} & \multicolumn{5}{|c|}{ RANK $^{6}$} \\
\hline & & & & & & OTS $^{7}$ & GOOD $^{8}$ & SED $^{9}$ & POOR $^{10}$ \\
\hline \multirow{31}{*}{ U } & \multirow{4}{*}{ U1 } & \multirow{4}{*}{0.1964} & A11 & 0.5495 & \multirow{4}{*}{ R11 } & 0.2 & 0.4 & 0.3 & 0.1 \\
\hline & & & A12 & 0.1293 & & 0.3 & 0.5 & 0.2 & 0 \\
\hline & & & A13 & 0.2476 & & 0.4 & 0.3 & 0.1 & 0.2 \\
\hline & & & A14 & 0.0736 & & 0.2 & 0.4 & 0.2 & 0.2 \\
\hline & \multirow{4}{*}{$\mathrm{U} 2$} & \multirow{4}{*}{0.0531} & A21 & 0.5767 & \multirow{4}{*}{ R22 } & 0.3 & 0.1 & 0.3 & 0.3 \\
\hline & & & A22 & 0.2216 & & 0.5 & 0.2 & 0.1 & 0.2 \\
\hline & & & A23 & 0.1251 & & 0.2 & 0.3 & 0.3 & 0.2 \\
\hline & & & A24 & 0.0766 & & 0.3 & 0.2 & 0.1 & 0.4 \\
\hline & \multirow{3}{*}{ U3 } & \multirow{3}{*}{0.3306} & A31 & 0.625 & \multirow{3}{*}{ R33 } & 0.1 & 0.3 & 0.2 & 0.4 \\
\hline & & & A32 & 0.2385 & & 0.4 & 0.3 & 0.1 . & 0.2 \\
\hline & & & A33 & 0.1365 & & 0.3 & 0.2 & 0.1 & 0.4 \\
\hline & \multirow{4}{*}{ U4 } & \multirow{4}{*}{0.0806} & A41 & 0.3248 & \multirow{4}{*}{ R44 } & 0.4 & 0.1 & 0.2 & 0.3 \\
\hline & & & A42 & 0.1486 & & 0.3 & 0.2 & 0.2 & 0.3 \\
\hline & & & A43 & 0.46 & & 0.4 & 0.2 & 0.1 & 0.3 \\
\hline & & & A44 & 0.0665 & & 0.4 & 0.2 & 0.3 & 0.1 \\
\hline & \multirow{5}{*}{ U5 } & \multirow{5}{*}{0.0352} & A51 & 0.4593 & \multirow{5}{*}{ R55 } & 0.3 & 0.2 & 0.1 & 0.4 \\
\hline & & & A52 & 0.2239 & & 0.1 & 0.3 & 0.2 & 0.4 \\
\hline & & & A53 & 0.1695 & & 0.2 & 0.1 & 0.3 & 0.4 \\
\hline & & & A54 & 0.0839 & & 0.3 & 0.1 & 0.2 & 0.4 \\
\hline & & & A55 & 0.0635 & & 0.2 & 0.2 & 0.2 & 0.4 \\
\hline & \multirow{6}{*}{ U6 } & \multirow{6}{*}{0.1029} & A61 & 0.3588 & \multirow{6}{*}{ R66 } & 0.1 & 0.3 & 0.4 & 0.2 \\
\hline & & & A62 & 0.1717 & & 0.3 & 0.1 & 0.3 & 0.3 \\
\hline & & & A63 & 0.117 & & 0.4 & 0.3 & 0.1 & 0.2 \\
\hline & & & A64 & 0.0763 & & 0.4 & 0.2 & 0.3 & 0.1 \\
\hline & & & A65 & 0.0554 & & 0.3 & 0.3 & 0.3 & 0.1 \\
\hline & & & A66 & 0.2208 & & 0.3 & 0.2 & 0.2 & 0.3 \\
\hline & \multirow{5}{*}{ U7 } & \multirow{5}{*}{0.1959} & A71 & 0.2491 & \multirow{5}{*}{ R77 } & 0.4 & 0.3 & 0.1 & 0.2 \\
\hline & & & A72 & 0.4360 & & 0.3 & 0.1 & 0.2 & 0.4 \\
\hline & & & A73 & 0.1481 & & 0.2 & 0.4 & 0.2 & 0.2 \\
\hline & & & A74 & 0.0716 & & 0.3 & 0.3 & 0.3 & 0.1 \\
\hline & & & A75 & 0.0951 & & 0.3 & 0.1 & 0.2 & 0.4 \\
\hline
\end{tabular}

表3 军民融合物流体系协调度评价数据。

1 EO: Evaluation objectives, 评价目标。

2 FEO: Evaluation objectives at the first level, 一级评价目标。

3 FW: Weight of first-level evaluation indicators relative to evaluation objectives, 一级评价指标相对评价目标的权重。

4 SEO: Evaluation objectives at the second level, 二级评价目标。

$5 \mathrm{SW}$ : Weight of second-level evaluation indicators relative to evaluation objectives, 二级评价指标相对评价目标的权重。

6 RANK: 状态等级隶属度。

7 OTS: Outstanding, 优秀。

8 GOOD: 良好。

9 SED: Secondary, 良好。

10 POOR: 较差。 
由评价结果的归一化处理和评价模型中构造的层次 模糊综合评价法, 从而得到指标层 $B_{1}$ 的模糊层次矩阵 $R_{11}$; 指标层 $B_{2}$ 的模糊层次矩阵 $R_{22}$; 指标层 $B_{3}$ 的模糊层次矩 阵 $R_{33}$; 指标层 $B_{4}$ 的模糊层次矩阵 $R_{44}$ ；指标层 $B_{5}$ 的模糊 层次矩阵 $R_{55}$; 指标层 $B_{6}$ 的模糊层次矩阵 $R_{66}$; 指标层 $B_{7}$ 的模糊层次矩阵 $R_{77}$ 。

\section{(1) 一级综合评价}

根据上文设定的模糊综合评价结果向量 $R_{1}=W_{1} \times R_{11}$, 得到物流运输体系评价指标集 $U_{A 1}$ 、物流保障体系评价指 标集 $U_{A 2}$ 、信息共享体系评价指标集 $U_{A 3}$ 、组织管理体系 评价指标集 $U_{A 4}$ 、物流运输运行机制评价指标集 $U_{A 5}$ 、物 流绩效评估系统评价指标集 $U_{A 6}$ 、应急响应体制机制评价 指标集 $U_{A 7}$ 的模糊综合评价结果向量分别为:

$$
\begin{aligned}
& R_{1}=W_{1} \times R_{11} \\
& R_{2}=W_{2} \times R_{22} \\
& R_{3}=W_{3} \times R_{33} \\
& R_{4}=W_{4} \times R_{44} \\
& R_{5}=W_{5} \times R_{55} \\
& R_{6}=W_{6} \times R_{66} \\
& R_{7}=W_{7} \times R_{77}
\end{aligned}
$$

其中 $W_{i}, i=(1,2,3,4,5,6)$ 为指标层中七个评估层级 $B_{1} B_{2} B_{3} B_{4} B_{5} B_{6} B_{7}$ 的指标权重, 分别为前文求出的:

$$
\begin{aligned}
& W_{1}=[0.5495,0.1293,0.2476,0.0736] \\
& W_{2}=[0.5767,0.2216,0.1251,0.0766] \\
& W_{3}=[0.625,0.2385,0.1365] \\
& W_{4}=[0.3248,0.1486,0.46,0.0665] \\
& W_{5}=[0.4593,0.2239,0.1695,0.0839,0.0635] \\
& W_{6}=[0.3588,0.1717,0.117,0.0763,0.0554,0.2208] \\
& W_{7}=[0.2491,0.4360,0.1481,0.0716,0.0951]
\end{aligned}
$$

将以上公式分别带入数据, 得到各准则相对于总体评 价目标的评价矩阵:

$$
\begin{aligned}
& R_{1}=[0.2625,0.3882,0.2302,0.1192] \\
& R_{2}=[0.3318,0.1548,0.2404,0.2730] \\
& R_{3}=[0.1989,0.2863,0.1625,0.3523] \\
& R_{4}=[0.3851,0.1675,0.1606,0.2867] \\
& R_{5}=[0.2319,0.1971,0.1710,0.4000] \\
& R_{6}=[0.2476,0.2359,0.2904,0.2261] \\
& R_{7}=[0.3101,0.2086,0.1822,0.299]
\end{aligned}
$$

由 7 个评价矩阵可以看出, 物流运输体系 $\mathrm{A} 1$ 相对于军 民融合物流体系协调度评价等级中优秀的隶属度为 0.2625 、良好的隶属度为 0.3882 、中等的隶属度为 0.2302
以及较差的隶属度为 0.1192 , 可认为物流运输体系 $\mathrm{A} 1$ 的评 价为良好居多。

而信息共享体系 $\mathrm{A} 3$ 评价等级中较差的隶属度为 0.3523 , 说明信息共享体系在相对于总目标军民融合物流 体系协调度贡献上发挥的效能较差, 在未来军民融合物流 体系的运行中应更加注重信息共享体系的构建及功能更 新, 使之高效地支撑起整个军民融合物流体系的日常运行。

在物流运输运行机制 $\mathrm{A} 5$ 中, 评价等级中的较差同样也 占据了 0.4000 个隶属度, 也意在说明相关军民融合部门应 更加完备物流运输运行相关机制的构建, 监督各体制机制 的运行状况, 查找其日常运行中的漏洞, 进行查漏补缺。

军民融合物流体系在应急响应层面发挥作用相对较 好, 应急响应体制机制A7的评价等级优秀占有 0.3101 个隶 属度, 但其评价等级中的较差仍占有 0.299 个隶属度, 原 因可能是军民融合物流体系协调度的发挥在处理公共应 急事件时社会覆盖面不够全面、人力资源配置不够科学合 理造成, 导致某些地区能很好的受到救助和支援, 某些地 区享受到的救助还不够, 针对这种情况, 相关部门应重视 物流体系处理应急事件时的全面性。

（2）二级综合评价。在一级综合评价的基础上，运 用与一级评价矩阵相同的算法进行二级评价矩阵计算, 具 体数据为 $B=W \times R=[0.2604,0.2647,0.1962,0.2734]$, 其 中 $\mathrm{W}=[0.1964,0.0531,0.3306,0.0806,0.0352,0.1029$, 0.1959] 已由前文求出。根据上文中已经将评语等级集 $V=$ [优秀, 良好, 中等, 差] 分别赋予相对应的分数值 $D=[1.0,0.75,0.5,0.25] \quad$ ，继而对 $B=[0.2604,0.2647,0.1962,0.2734]$ 进行加权求平均值, 就 会得到最终评定结果 0.6254 , 属于隶属度为 $[0.5,0.75]$ 之间, 因此该军民融合物流系统耦合协调度属于 $v_{2}=$ 良好这个 级别, 军民融合物流体系的协调度需要从整体上进行提升, 并结合上文的一级综合评价的结果, 相关单位和部门应将 军民融合物流体系的运营发展着重于物流运输体系、信息 共享体系以、物流运输运行机制以及应急响应体制机制上。

\section{5. 结论}

本文从系统学角度出发, 以军事物流系统和民用物流 系统的各物流资源相互耦合协调度为评价总目标, 在以往 的军民融合物流指标体系的准则层中根据国家面临的疫 情现状增加了应急响应体制机制, 并在此评价模型基础上 采用模糊层次分析法对军民融合物流系统的相融与运行 状况做出量化评价, 为相关部门对军民融合物流系统的改 进做理论指导, 具有一定的可行性和可靠性。

\section{参考文献}

[1] 陈春燕. 军事物资军地物流耦合研究 [D]. 南京理工大学, 2012。 
[2] KASILINGAM R G. LOGISTICS AND TRANSPORTATION: DESIGN AND PLANNING[J]. Logistics, 1998。

[3] FREDLAND J E. Outsourcing military force: a transactions cost perspective on the role of military companies[J].Defence and Peace Economics, 2004, 15(3): 205-219。

[4] 古贞,谭清美. 军民融合物流体系构建研究 [J]. 科技管理研 究,2019,39(20):228-235。

[5] 曹景建, 姜大立. 基于CALS的军民融合物流信息体系构建 研究 [J]. 商品储运与养护,2008,30(8)：32-34。

[6] 王凤忠, 宋大东, 赵锐. 军民融合物流标准体系建设的思 考 [J].物流技术，2018(2)：140-143。

[7] 王宗喜. 军地物流资源统筹的战略思考[J].中国流通经济, 2012,26(10): 4-7。

[8] 袁科峰,张晓霞. 军民融合式物流系统耦合协调量化分析 [J]. 湖北文理学院学报,2015,36(08):23-26。

[9] 陈海艳,王开勇,高波. 军事物流军民融合标准体系现状分 析[J].物流技术,2019,38(03):141-146。

[10] 兰继斌,徐扬,霍良安,刘家忠. 模糊层次分析法权重研究 [J]. 系统工程理论与实践,2006(09):107-112。

[11] 周超. 基于模糊层次分析法的高校信息公开绩效评价[D]. 黑龙江大学,2013：28-50。

[12] 曲晓平. 基于模糊层次分析的火电厂选址研究与应用 [D]. 北京: 华北电力大学, 2006:10-14。

[13] 叶珍. 基于AHP的模糊综合评价方法研究及应用[D].广州: 华南理工大学.2010:22-27。

[14] 陈亚琼,吴文博. 基于模糊层次分析法的理工科大学生创业 能力评价研究 [J]. 湖南工程学院学报 (自然科学 版),2019,29(04):49-53。

[15] 李吴. 应急物流保障效能评估及其应用研究[D].兰州交通 大学,2013。

[16] Stanislav Karapetrovic, E.S. Rosenbloom. A quality control approach to consistency paradoxes in AHP[J]. European Journal of Operational Research, 119(3):704-718。

[17] 王升,李利平,成帅,胡慧江,张明光,文桃.基于改进属性区间 辨识模型的隧道突涌水灾害风险评价方法（英文） [J].Journal of Central South University,2020,27(02):517-530。

[18] Kanwarpreet SINGH,Virender KUMAR. Hazard assessment of landslide disaster using information value method and analytical hierarchy process in highly tectonic Chamba region in bosom of Himalaya[J]. Journal of Mountain Science, 2018,15(04):808-824。

[19] Zhang, Zhicai, Chen, et al. Analysis on decision-making model of plan evaluation based on grey relation projection and combination weight algorithm[J]. Journal of Systems Engineering \& Electronics, 2018。

\section{作者简介}

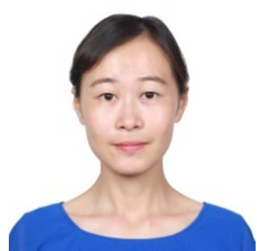

徐影（1992-）, 女, 在读研究生。研 究方向：系统优化设计。

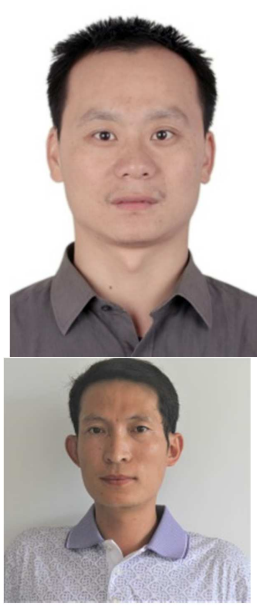

王畑琦（1979-）, 男, 教授, 博士学 历。研究方向: 信息融合、靶场数据处 理、系统优化设计。

潘晓刚（1979-）, 男, 教授, 博士学 历。研究方向: 战场感知信息处理、系 统优化设计。

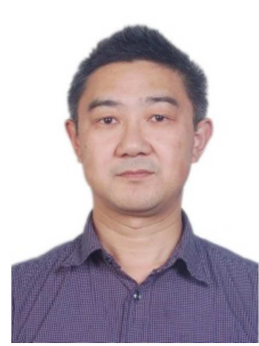

周海银（1965-）, 男, 教授, 博士学 历。研究方向: 信息融合、靶场数据处 理、系统优化设计。

何章鸣（1985-）, 男, 副教授, 博士 学历。研究方向: 信息融合、靶场数据 处理、系统优化设计。

侯博文（1995-）, 男, 在读博士。研 究方向: 航天器自主导航、系统优化设 计。 